\title{
Guided de-escalation of antiplatelet treatment in patients with acute coronary syndrome undergoing percutaneous coronary intervention (TROPICAL-ACS): a randomised, open-label, multicentre trial
}

\author{
Dirk Sibbing*, Dániel Aradi*, Claudius Jacobshagen, Lisa Gross, Dietmar Trenk, Tobias Geisler, Martin Orban, Martin Hadamitzky, Béla Merkely, \\ Róbert Gábor Kiss, András Komócsi, Csaba A Dézsi, Lesca Holdt, Stephan B Felix, Radoslaw Parma, Mariusz Klopotowski, Robert H G Schwinger, \\ Johannes Rieber, Kurt Huber, Franz-Josef Neumann, Lukasz Koltowski, Julinda Mehilli, Zenon Huczek, Steffen Massberg, on behalf of the \\ TROPICAL-ACS Investigators $\dagger$
}

\section{Summary}

Background Current guidelines recommend potent platelet inhibition with prasugrel or ticagrelor for 12 months after an acute coronary syndrome managed with percutaneous coronary intervention (PCI). However, the greatest antiischaemic benefit of potent antiplatelet drugs over the less potent clopidogrel occurs early, while most excess bleeding events arise during chronic treatment. Hence, a stage-adapted treatment with potent platelet inhibition in the acute phase and de-escalation to clopidogrel in the maintenance phase could be an alternative approach. We aimed to investigate the safety and efficacy of early de-escalation of antiplatelet treatment from prasugrel to clopidogrel guided by platelet function testing (PFT).

Methods In this investigator-initiated, randomised, open-label, assessor-blinded, multicentre trial (TROPICAL-ACS) done at 33 sites in Europe, patients were enrolled if they had biomarker-positive acute coronary syndrome with successful PCI and a planned duration of dual antiplatelet treatment of 12 months. Enrolled patients were randomly assigned (1:1) using an internet-based randomisation procedure with a computer-generated block randomisation with stratification across study sites to either standard treatment with prasugrel for 12 months (control group) or a stepdown regimen ( 1 week prasugrel followed by 1 week clopidogrel and PFT-guided maintenance therapy with clopidogrel or prasugrel from day 14 after hospital discharge; guided de-escalation group). The assessors were masked to the treatment allocation. The primary endpoint was net clinical benefit (cardiovascular death, myocardial infarction, stroke or bleeding grade 2 or higher according to Bleeding Academic Research Consortium [BARC]) criteria) 1 year after randomisation (non-inferiority hypothesis; margin of 30\%). Analysis was intention to treat. This study is registered with ClinicalTrials.gov, number NCT01959451, and EudraCT, 2013-001636-22.

Findings Between Dec 2, 2013, and May 20, 2016, 2610 patients were assigned to study groups; 1304 to the guided deescalation group and 1306 to the control group. The primary endpoint occurred in 95 patients $(7 \%)$ in the guided deescalation group and in 118 patients $(9 \%)$ in the control group $\left(\mathrm{p}_{\text {non-inferionity }}=0.0004\right.$; hazard ratio $[\mathrm{HR}] \mathbf{0 . 8 1}[95 \% \mathrm{Cl}$ $0 \cdot 62-1.06], p_{\text {superionity }}=0 \cdot 12$ ). Despite early de-escalation, there was no increase in the combined risk of cardiovascular death, myocardial infarction, or stroke in the de-escalation group (32 patients [3\%]) versus in the control group (42 patients [3\%]; $\mathrm{p}_{\text {non-nereroity }}=0 \cdot 0115$ ). There were 64 BARC 2 or higher bleeding events (5\%) in the de-escalation group versus 79 events (6\%) in the control group (HR $0 \cdot 82$ [95\% CI 0 - 59-1·13]; $\mathrm{p}=0 \cdot 23$ ).

Interpretation Guided de-escalation of antiplatelet treatment was non-inferior to standard treatment with prasugrel at 1 year after PCI in terms of net clinical benefit. Our trial shows that early de-escalation of antiplatelet treatment can be considered as an alternative approach in patients with acute coronary syndrome managed with PCI.

Funding Klinikum der Universität München, Roche Diagnostics, Eli Lilly, and Daiichi Sankyo.

\section{Introduction}

Activation of blood platelets plays a key part both in the initiation and during the early phase of an acute coronary syndrome. Consequently, clinical outcomes of patients with acute coronary syndrome undergoing percutaneous coronary intervention (PCI) have been significantly improved and ischaemic risk has been reduced with the use of potent $\mathrm{P}_{12} \mathrm{Y}_{12}$ receptor inhibitors like prasugrel or ticagrelor, albeit at the expense of an increased bleeding risk. ${ }^{1-4}$ Current acute coronary syndrome guidelines recommend potent $\mathrm{P}_{2} \mathrm{Y}_{12}$ receptor inhibitors for 1 year in patients with acute coronary syndrome managed by PCI. ${ }^{5}$ However, the greatest benefits of these potent drugs are seen early, when the risk of ischaemic complications is highest, while most haemorrhagic events with potent platelet inhibitors arise during chronic treatment. ${ }^{3.4}$ This rationale has fuelled interest in strategies of step-wise de-escalation ${ }^{6}$ using potent ${\mathrm{P} 2 \mathrm{Y}_{12}}_{1}$ inhibitors only in the early phase of treatment,
Published Online August 27, 2017 http://dx.doi.org/10.1016/ S0140-6736(17)32155-4 See Online/Comment http://dx.doi.org/10.1016/ S0140-6736(17)32279-1 *Contributed equally †Investigators listed in the appendix

Department of Cardiology, LMU München, Munich, Germany (Prof D Sibbing MD, L Gross MD, M Orban MD, Prof) Mehilli MD, Prof S Massberg MD); DZHK (German Centre for Cardiovascular Research) Munich Heart Alliance, Munich, Germany (Prof D Sibbing, Prof J Mehilli, Prof S Massberg); Heart Centre Balatonfüred and Heart and Vascular Centre, Semmelweis University, Budapest, Hungary (D Aradi MD); Department of Cardiology und Pneumology, Heart Centre/Georg-AugustUniversity Göttingen, Göttingen, Germany (C Jacobshagen MD); Department of Cardiology and Angiology II, University Heart Centre Freiburg, Bad Krozingen, Germany (Prof D Trenk PhD, Prof F-J Neumann MD); University Hospital Tübingen, Department of Cardiology and Cardiovascular Disease, Tübingen, Germany (ProfT Geisler MD); Department of Radiology, Deutsches Herzzentrum, München, Germany (M Hadamitzky MD); Heart and Vascular Centre, University of Semmelweis, Budapest, Hungary (Prof B Merkely MD); Department of Cardiology, Military Hospital, Budapest, Hungary (Prof R G Kiss MD); 
Department of Interventional Cardiology, Heart Institute, University of Pécs, Pécs, Hungary (Prof A Komocsi MD); Department of Cardiology, Petz Aladár County Teaching Hospital, Győr, Hungary (C A Dézsi MD); Institute of Laboratory Medicine, University Hospital, LMU Munich, Munich, Germany (Prof L Holdt MD); Department of Internal Medicine B, University Medicine Greifswald, Germany and DZHK, Greifswald, Germany (Prof S B Felix MD): 3rd Department of Cardiology, Medical University of Silesia, Katowice, Poland

(R Parma MD); Department of Interventional Cardiology and

Angiology, Institute of Cardiology, Warsaw, Poland (M Klopotwoski MD); Medizinische Klinik II, Klinikum Weiden, Kliniken

Nordoberpfalz AG, Weiden, Germany

(Prof R H G Schwinger MD); Heart Centre MunichBogenhausen, Department of Cardiology and Intensive Care Medicine, Munich, Germany (J Rieber MD); 3rdMedical Department, Cardiology and Intensive Care Medicine, and Sigmund Freud Private University, Medical School, Wien, Austria

(Prof K Huber MD); and 1st Department of Cardiology, Medical University of Warsaw, Warsaw, Poland (Z Huczek MD, L Koltowksi MD) Correspondence to: Prof Dirk Sibbing, Department of Cardiology, LMU München, Marchioninistraße 15, 81377 Munich, Germany dirk.sibbing@med.unimuenchen.de

See Online for appendix

\section{Research in context}

\section{Evidence before this study}

International guidelines recommend potent platelet inhibition with prasugrel or ticagrelor in the first year after an acute coronary syndrome. Despite these recommendations, a regimen implying early de-escalation from potent antiplatelet agents to the less potent and off-patent clopidogrel is appealing both from a conceptual and economic perspective. We searched MEDLINE on July 1, 2017, for articles in English with the search terms "antiplatelet treatment de-escalation", "switching antiplatelet therapy", and "acute coronary syndrome guidelines", and found only a few studies with a focus on clinical outcomes (TRANSLATE-ACS, SCOPE registry, TOPIC trial). Data from the TRANSLATE-ACS registry showed that de-escalation is common clinical practice with up to $28 \%$ of patients with acute coronary syndrome switching from potent platelet inhibition down to clopidogrel within the first year post discharge on their own or their physician's initiative. The reasons for de-escalation most predominantly include adverse events and issues with reimbursement or availability of potent platelet inhibitors. However, to date, evidence supporting safety and efficacy and thereby justifying de-escalation is lacking and even conflicting While data from a single registry (SCOPE) pointed towards potential hazards of de-escalating treatment after acute coronary syndrome, a smaller single-centre randomised trial (TOPIC) favoured uniform de-escalation of treatment in eventfree patients with acute coronary syndrome at 1 month after percutaneous coronary intervention, mainly driven by a reduction of Bleeding Academic Research Consortium (BARC) grade 2 or higher bleeding in patients receiving de-escalated antiplatelet treatment.

\section{Added value of this study}

To the best of our knowledge, TROPICAL-ACS is the first randomised trial to investigate a strategy of early and guided de-escalation of $\mathrm{P}_{2} \mathrm{Y}_{12}$ inhibition in patients with acute coronary syndrome. The trial population represents a high-risk cohort of biomarker-positive patients with acute coronary syndrome including more than 1400 patients with ST-elevation myocardial infarction. De-escalation guided by platelet function testing (PFT) ensured sufficient platelet inhibition in all patients with acute coronary syndrome in the experimental arm, with about $60 \%$ of patients continuing on clopidogrel treatment and $40 \%$ of patients requiring escalation back to prasugrel. By showing non-inferiority of PFT-guided de-escalation compared with a standard of potent platelet inhibition for 12 months, our trial provides important evidence justifying tailored de-escalation as an alternative strategy in patients with acute coronary syndrome after coronary stenting. Study results are applicable to all scenarios of de-escalation, regardless of whether the need to de-escalate arises from clinical or economic issues. PFT results can help to justify de-escalation in clopidogrel responders, while they might also help to overcome budgetary issues for patients that would require escalation back to prasugrel.

\section{Implications of all the available evidence}

Based on all the available evidence, uniform and potent platelet inhibition in patients with acute coronary syndrome probably remains standard of care, because TROPICAL-ACS did not show superiority of de-escalation. Notwithstanding, alternative treatment concepts are desired for a significant proportion of patients in clinical practice. Our trial now supports the safety and efficacy of an early and guided de-escalation of platelet inhibition in patients with acute coronary syndrome as an alternative strategy that can be followed whenever necessary for medical or socioeconomic reasons. The regimen of guided treatment seems also practical beyond the framework of a randomised controlled trial, because patients in many countries worldwide typically have planned outpatient visits within the first weeks after an acute coronary syndrome. and using the less potent clopidogrel during the chronic treatment course. However, to date, the evidence supporting safety and efficacy and thereby justifying deescalation is limited and the few available data from smaller studies are conflicting..$^{78}$ Despite the absence of unequivocal evidence, de-escalation of antiplatelet therapy after acute coronary syndrome is quite common in clinical practice $^{8-11}$ and about $15-28 \%$ of patients with acute coronary syndrome ${ }^{9}$ are switched from potent to less potent treatment after discharge. This occurs for several reasons, including adverse bleeding events or nonbleeding events, a perceived high bleeding risk, and economic issues favouring off-patent clopidogrel. ${ }^{1,9,11}$

Nevertheless, any de-escalation of antiplatelet therapy from a potent $\mathrm{P} 2 \mathrm{Y}_{12}$ inhibitor to the less potent clopidogrel should account for large response variability of the latter ${ }^{12}$ and the consequential issue of high on-treatment platelet reactivity (HPR), which exists in a substantial proportion of patients with acute coronary syndrome. ${ }^{13-15}$ Patients with HPR exhibit an increased risk for recurrent ischaemic events, including myocardial infarction and stent thrombosis. ${ }^{13-15}$ Hence, platelet function testing (PFT) could serve to make de-escalation safer by identifying patients with HPR on clopidogrel, who might be exposed to an increased risk of thrombotic events due to insufficient $\mathrm{P}_{2} \mathrm{Y}_{12}$ inhibition and who should therefore continue potent $\mathrm{P} 2 \mathrm{Y}_{12}$ inhibitors like prasugrel. Thus, we aimed to investigate the safety and efficacy of a PFT-guided early de-escalation of antiplatelet treatment compared with standard prasugrel therapy in patients with acute coronary syndrome undergoing PCI.

\section{Methods}

\section{Study design and patients}

The Testing Responsiveness To Platelet Inhibition On Chronic Antiplatelet Treatment For Acute Coronary Syndromes (TROPICAL-ACS) trial was an investigatorinitiated, randomised, parallel-group, open-label, 
assessor-blinded, multicentre trial that was done at 33 European sites (two in Austria, 20 in Germany, seven in Hungary, and four in Poland) and had an academic sponsor (Klinikum der Universität München). Patients were eligible if they had biomarker-positive acute coronary syndrome with a successful PCI (defined as a post-PCI diameter stenosis $<20 \%$ and thrombolysis in myocardial infarction [TIMI] flow $\geq 2$ ), and planned treatment of prasugrel for 12 months after the procedure. The appendix (p 2) lists all inclusion and exclusion criteria; the study protocol with further details has been published previously. ${ }^{16}$

Patients provided written informed consent. An independent data safety monitoring board (DSMB) oversaw the trial and had full access to unblinded data. Study monitoring for all patients was done by an external service provider (Münchner Studienzentrum, MSZ, Munich, Germany). The institutional ethics committee of each participating site, as well as the competent national agencies approved the trial. The study was conducted in accordance with the principles of the Declaration of Helsinki.

\section{Randomisation and masking}

Using an internet-based randomisation procedure with a computer-generated block randomisation with stratification across study sites, patients with acute coronary syndrome were randomly assigned before planned discharge in a 1:1 fashion to the two study groups of either PFT-guided de-escalation or control group. Patients were considered enrolled in the study and eligible for the final intention-to-treat analysis at the time of randomisation. Figure 1 summarises the study flow of the TROPICAL-ACS study. Patients in the control group received a standard care of 12 month prasugrel treatment at a dose of $10 \mathrm{mg}$ or $5 \mathrm{mg}$ according to the label and the current guideline recommendations. ${ }^{5,17}$ Patients in the de-escalation group received a post-discharge treatment, consisting of 1 week prasugrel treatment (10 mg or $5 \mathrm{mg}$ per day) followed by 1 week of clopidogrel treatment (75 mg per day) and a platelet function measurement (on clopidogrel) 2 weeks after hospital discharge (PFT-guided de-escalation group). Based on PFT results in the guided de-escalation group, patients were either switched back to prasugrel, when a status of HPR with insufficient platelet inhibition was detected, whereas patients with sufficient platelet inhibition (no HPR) continued with clopidogrel.

Study group-related treatment was planned to start on the day after discharge and study drugs for the first 14 days post discharge were packed and provided by the pharmacy department of the Klinikum der Universität München (Munich, Germany). We deemed this necessary to guarantee an exact intake of tablets during a time frame covering the switch of treatment in the guided deescalation group. For both groups, three extra tablets (provisional medication) were included in the box for week 2 to ensure flexibility regarding the timing of the first follow-up visit out to day 17. Treatment after day 14 post discharge until 12 months was planned according to the assigned randomisation and HPR status in the guided de-escalation group and was prescribed by the patient's primary care physician in both study groups. Further details on randomisation procedures and study drugs were published previously. ${ }^{16}$

\section{Procedures}

2 weeks after discharge from the primary care hospital, where the index PCI was done, all patients had an outpatient visit. In addition, patients were contacted by phone call at 30 days, 6 months, and 12 months after randomisation. These calls were made to explore study endpoints and adverse events and to assess adherence to the assigned antiplatelet therapy using a study-specific designed standardised questionnaire. In case of a suspected clinical event all source data were collected to allow for precise event adjudication by the event adjudication committee.

For the on-site follow-up visit, participants from both study groups underwent planned and prescheduled blood sampling for PFT under steady-state conditions. The Multiplate analyser (Roche Diagnostics, Rotkreuz, Switzerland) was used for testing. Details of this method and its predictive value have been published previously. ${ }^{13,14,16}$ A status of HPR was defined based on the results of previous studies and the consensus documents of the Working Group on HPR as an adenosine diphosphate test aggregation value of 46 units or higher on the Multiplate analyser..$^{13,14}$ In the control group, testing was done only for observational purposes and results did not affect drug selection or dosing. In the guided deescalation group, testing results determined the further course of treatment: patients with HPR were immediately switched back to prasugrel, while those without HPR continued on clopidogrel (figure 1).

\section{Outcomes}

The primary endpoint was a combined ischaemic and bleeding endpoint (net clinical benefit), which was the composite of death from cardiovascular causes (all deaths were assumed cardiovascular in nature unless a noncardiovascular cause could be clearly provided), myocardial infarction (defined according to the 3rd universal definition of myocardial infarction ${ }^{18}$ ), stroke, and bleeding grade 2 or higher defined according to Bleeding Academic Research Consortium (BARC) criteria ${ }^{19}$ at 12 months after randomisation. The key secondary endpoint was defined as BARC class 2 or higher bleeding events at 12 months. Further secondary endpoints included the ischaemic components (combined and singular) of the primary endpoint (cardiovascular death, myocardial infarction, and stroke), stent thrombosis defined according to Academic Research Consortium (ARC) criteria, ${ }^{20}$ the incidence of death from any cause, and urgent ischaemiadriven revascularisation at 12 months. With respect to 


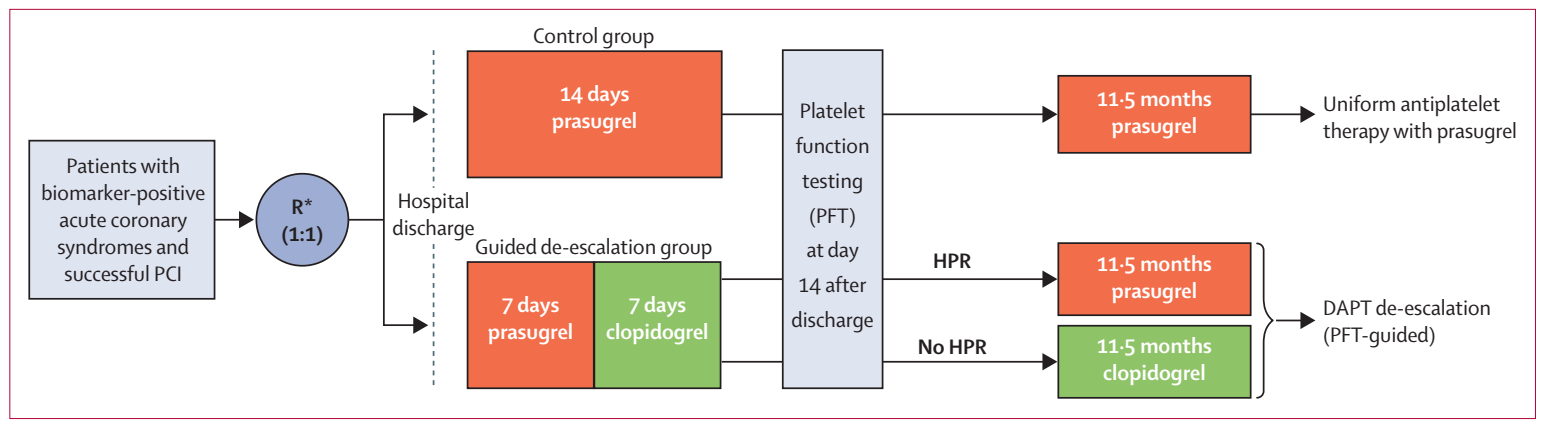

Figure 1: Study design and groups

The figure shows the control group and the experimental group with guided de-escalation of antiplatelet treatment. Patients were randomly assigned (1:1) after $\mathrm{PCl}$ and directly before planned discharge from hospital. On-treatment platelet reactivity was measured in both study groups. In the control group, on-prasugrel testing results had no effect on further treatment, which was prasugrel for all patients. Based on the testing results in the guided de-escalation group (on clopidogrel treatment), the further treatment was determined at day 14 post discharge. Protocol-mandated treatment required clopidogrel in no-HPR patients and a switch back to prasugrel in HPR patients. $\mathrm{PCl}=$ percutaneous coronary intervention. $\mathrm{HPR}=$ high on-treatment platelet reactivity. $\mathrm{R}^{*}=$ randomisation. $\mathrm{DAPT}=$ dual antiplatelet therapy.

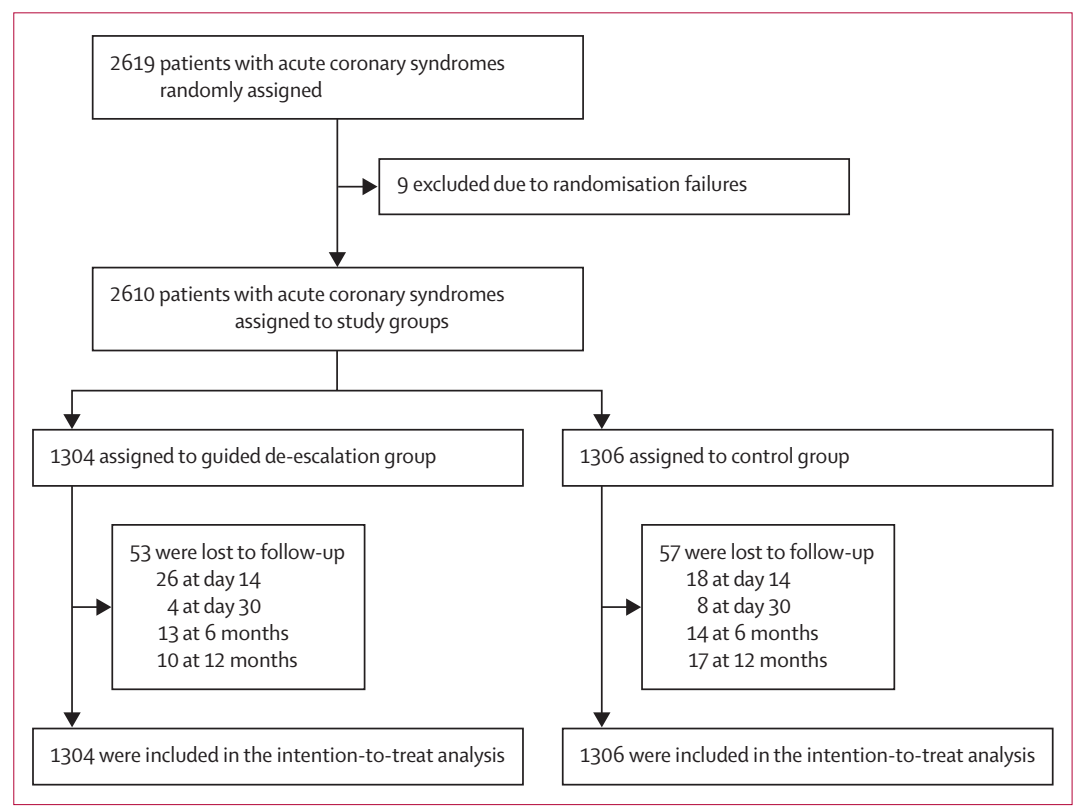

Figure 2: Trial profile non-inferiority margin of $30 \%$ was estimated, which is in accordance with non-inferiority margins used in contemporary trials of antithrombotic treatment in cardiovascular diseases. ${ }^{22,23}$ Sample size calculations (nQuery Advisory, Statistical Solutions, Farmer's Cross, Cork, Ireland) were done based on a one-sided type 1 error of $5 \%$ and a power of $80 \%$. For the primary endpoint assumptions, 1172 patients in each group were needed. Assuming an incidence of BARC 2 or higher bleeding in the control group of $4.9 \%$ and an expected reduction of BARC 2 or higher bleeding by $45 \%$ in the de-escalation group, 1179 patients per group would be required to show superiority (based on two-sided type 1 error of $5 \%$ and a power of $80 \%$ for the key secondary endpoint (BARC 2 or higher bleeding). To compensate for losses to follow-up and to be powered for the primary and secondary endpoint assessment the enrolment of a total of 2600 patients (1300 patients per group) was planned. All analyses were done on an intention-to-treat basis. In addition, per-protocol analyses were done. Differences in endpoints were analysed in Cox-regression models for survival analysis. In all cases of the use of the Cox proportional hazards model, the proportional hazards assumption was met. Kaplan-Meier plots were generated to visualise the risk of outcome events in both groups. Binary and other categorical variables were compared using Fisher's exact test and $\chi^{2}$ test, respectively, for continuous data two-sided unpaired Wilcoxon test or Student's $t$ test were used as appropriate. Data were analysed with $\mathrm{R}$ version 3.3.0.

\section{Statistical analysis}

The study was designed to show non-inferiority for the guided de-escalation group versus the control group regarding the primary composite endpoint. Considering the results of a landmark analysis from the TRITONTIMI 38 trial, $^{3}$ based on the incidence of early versus late major bleeding events ${ }^{3}$ and based on the incidence of BARC 2 or higher bleeding complications in a PCI cohort,$^{21}$ the incidence of the primary endpoint of this study was assumed to be $10.5 \%$ in the control group. A

\section{Role of the funding source}

The funders of this study had no role in study design, collection of data and data analysis, or writing of the manuscript. DS and SM had full access to the data and take full responsibility for the decision to submit for publication.

This study is registered with ClinicalTrials.gov, number NCT01959451, and EudraCT, 2013-001636-22. 


\begin{tabular}{|c|c|c|}
\hline & $\begin{array}{l}\text { Control group } \\
(\mathrm{n}=1306)\end{array}$ & $\begin{array}{l}\text { Guided de-escalation } \\
\text { group }(n=1304)\end{array}$ \\
\hline Age (years) & $58 \cdot 5(10 \cdot 2)$ & $59 \cdot 0(10 \cdot 1)$ \\
\hline Men & $283(22 \%)$ & $275(21 \%)$ \\
\hline Body-mass index $\left(\mathrm{kg} / \mathrm{m}^{2}\right)$ & $28 \cdot 4(5 \cdot 0)$ & $28 \cdot 1(4 \cdot 5)$ \\
\hline White & 1295 (99\%) & $1295(99 \%)$ \\
\hline $\begin{array}{l}\text { Previous percutaneous } \\
\text { coronary intervention }\end{array}$ & $186(14 \%)$ & $173(13 \%)$ \\
\hline $\begin{array}{l}\text { Previous coronary } \\
\text { artery bypass surgery }\end{array}$ & $46(4 \%)$ & $39(3 \%)$ \\
\hline $\begin{array}{l}\text { Previous myocardial } \\
\text { infarction }\end{array}$ & $153(12 \%)$ & $140(11 \%)$ \\
\hline $\begin{array}{l}\text { History of peripheral artery } \\
\text { occlusive disease }\end{array}$ & $39(3 \%)$ & $46(4 \%)$ \\
\hline $\begin{array}{l}\text { History of coronary } \\
\text { artery disease }\end{array}$ & $204(16 \%)$ & $175(13 \%)$ \\
\hline Renal insufficiency & $34(3 \%)$ & $33(3 \%)$ \\
\hline Diabetes mellitus & $287(22 \%)$ & $240(18 \%)$ \\
\hline Current smoker & $591(45 \%)$ & $591(45 \%)$ \\
\hline Arterial hypertension & $806(62 \%)$ & $793(61 \%)$ \\
\hline Hyperlipidaemia & $529(41 \%)$ & $546(42 \%)$ \\
\hline $\begin{array}{l}\text { Family history of } \\
\text { coronary artery disease }\end{array}$ & $466(36 \%)$ & $419(32 \%)$ \\
\hline Haemoglobin (g/dL) & $14 \cdot 2(1 \cdot 6)$ & $14 \cdot 3(1 \cdot 6)$ \\
\hline Creatinine $(\mathrm{mg} / \mathrm{dL})$ & $0.9(0.2)$ & $0.9(0.3)$ \\
\hline \multicolumn{3}{|l|}{ Medication at admission } \\
\hline Aspirin & $343(26 \%)$ & $303(23 \%)$ \\
\hline ADP receptor antagonist & $76(6 \%)$ & $71(5 \%)$ \\
\hline Beta blocker & $368(28 \%)$ & $378(29 \%)$ \\
\hline ACE inhibitor & $341(26 \%)$ & $357(27 \%)$ \\
\hline $\begin{array}{l}\text { Angiotensin }{ }_{1} \text { receptor } \\
\text { antagonist }\end{array}$ & $161(12 \%)$ & $173(13 \%)$ \\
\hline Calcium antagonist & $166(13 \%)$ & $178(14 \%)$ \\
\hline Proton-pump inhibitor & $175(13 \%)$ & $174(13 \%)$ \\
\hline Statin treatment & $298(23 \%)$ & $286(22 \%)$ \\
\hline \multicolumn{3}{|c|}{$\begin{array}{l}\text { Data are } n(\%) \text { or mean (SD). ADP=adenosine diphosphate. } \\
A C E=\text { angiotensin-converting-enzyme. }\end{array}$} \\
\hline
\end{tabular}

\section{Results}

Between Dec 2, 2013, and May 20, 2016, 2610 eligible patients with acute coronary syndrome were randomly assigned at 33 European PCI sites (figure 2). These patients constitute the intention-to-treat population, in which 1306 patients were randomly assigned to the control group and 1304 patients to the guided deescalation group. Mean age of patients was 59 years (SD 10) and 558 (21\%) were women. 1453 (56\%) patients presented with ST-elevation myocardial infarction (STEMI). Table 1 summarises the baseline characteristics of the study cohort and table 2 provides an overview of procedural characteristics of the index PCI.

For the pre-scheduled follow-up visit at 2 weeks after hospital discharge the follow-up rate was $98 \%$ in the guided de-escalation group and $99 \%$ in the control group. In the guided de-escalation group, a status of HPR was

\begin{tabular}{|c|c|c|}
\hline & $\begin{array}{l}\text { Control group } \\
(\mathrm{n}=1306)\end{array}$ & $\begin{array}{l}\text { Guided de-escalation } \\
\text { group }(n=1304)\end{array}$ \\
\hline \multicolumn{3}{|l|}{ Cause of PCI } \\
\hline STEMI & $722(55 \%)$ & $731(56 \%)$ \\
\hline NSTEMI & $584(45 \%)$ & $573(44 \%)$ \\
\hline \multicolumn{3}{|l|}{ Access site } \\
\hline Brachial & $3(<1 \%)$ & 0 \\
\hline Femoral & $541(41 \%)$ & $523(40 \%)$ \\
\hline Radial & $762(58 \%)$ & $781(60 \%)$ \\
\hline \multicolumn{3}{|c|}{ Number of diseased coronary vessels } \\
\hline 1 & $682(52 \%)$ & $659(51 \%)$ \\
\hline 2 & $345(26 \%)$ & $359(28 \%)$ \\
\hline 3 & $279(21 \%)$ & $286(22 \%)$ \\
\hline \multicolumn{3}{|c|}{ Anticoagulant agent used for $\mathrm{PCl}$} \\
\hline Bivalirudin & $55(4 \%)$ & $54(4 \%)$ \\
\hline $\begin{array}{l}\text { Low molecular } \\
\text { weight heparin }\end{array}$ & $70(5 \%)$ & $72(6 \%)$ \\
\hline Unfractionated heparin & $1181(90 \%)$ & $1178(90 \%)$ \\
\hline $\begin{array}{l}\text { Use of glycoprotein IIb/IIIa } \\
\text { antagonist }\end{array}$ & $247(19 \%)$ & $244(19 \%)$ \\
\hline \multicolumn{3}{|l|}{ TIMI flow grade before $\mathrm{PCI}$} \\
\hline 0 & $512(39 \%)$ & $511(39 \%)$ \\
\hline 1 & $171(13 \%)$ & $173(13 \%)$ \\
\hline 2 & $302(23 \%)$ & $321(25 \%)$ \\
\hline 3 & $321(25 \%)$ & $299(23 \%)$ \\
\hline \multicolumn{3}{|l|}{ Coronary vessels treated } \\
\hline Left main & $12(1 \%)$ & $29(2 \%)$ \\
\hline Left anterior descending & $556(43 \%)$ & $562(43 \%)$ \\
\hline Left circumflex & $253(19 \%)$ & $266(20 \%)$ \\
\hline Right coronary artery & $450(35 \%)$ & $433(33 \%)$ \\
\hline Coronary bypass graft & $35(3 \%)$ & $14(1 \%)$ \\
\hline \multicolumn{3}{|c|}{ AHA/ACC classification of lesions } \\
\hline A & $155(12 \%)$ & $161(12 \%)$ \\
\hline B1 & $425(33 \%)$ & $434(33 \%)$ \\
\hline B2 & $340(26 \%)$ & $327(25 \%)$ \\
\hline c & $386(30 \%)$ & $382(29 \%)$ \\
\hline Ostial lesion & $98(8 \%)$ & $97(7 \%)$ \\
\hline Bifurcation lesion & $195(15 \%)$ & $204(16 \%)$ \\
\hline \multicolumn{3}{|l|}{ Stent type } \\
\hline DES & $1002(77 \%)$ & $1003(77 \%)$ \\
\hline BMS & $208(16 \%)$ & $224(17 \%)$ \\
\hline BVS & $83(6 \%)$ & $68(5 \%)$ \\
\hline None (PTCA only) & $13(1 \%)$ & $9(1 \%)$ \\
\hline \multicolumn{3}{|l|}{ TIMI flow grade after $\mathrm{PCI}$} \\
\hline 2 & $38(3 \%)$ & $38(3 \%)$ \\
\hline 3 & $1268(97 \%)$ & $1266(97 \%)$ \\
\hline \multicolumn{3}{|c|}{$\begin{array}{l}\text { Data are n (\%). STEMI=ST-segment elevation myocardial infarction. } \\
\text { NSTEMI=non-ST-segment elevation myocardial infarction. } \mathrm{PCl} \text { =percutaneous } \\
\text { coronary intervention. TIMI=thrombolysis in myocardial infarction. } \\
\text { AHA=American Heart Association. } \mathrm{ACC}=\text { American College of Cardiology. } \\
\text { DES=drug-eluting stent. BMS=bare metal stent. BVS=bioresorbable vascular } \\
\text { scaffold. PTCA=percutaneous transluminal coronary angioplasty. }\end{array}$} \\
\hline
\end{tabular}

noted in 511 patients $(39 \%$ of the intention-to-treat population). In line with the protocol, 506 (99\%) of the 


\begin{tabular}{|c|c|c|c|c|}
\hline & $\begin{array}{l}\text { Control group } \\
(n=1306)\end{array}$ & $\begin{array}{l}\text { Guided } \\
\text { de-escalation } \\
\text { group } \\
(\mathrm{n}=1304)\end{array}$ & $\begin{array}{l}\text { Hazard ratio } \\
(95 \% \mathrm{Cl})\end{array}$ & $p$ value \\
\hline \multicolumn{5}{|l|}{ Net clinical benefit } \\
\hline $\begin{array}{l}\text { Primary endpoint (cardiovascular } \\
\text { death, myocardial infarction, } \\
\text { stroke, bleeding BARC } \geq 2 \text { ) }\end{array}$ & $118(9 \%)$ & $95(7 \%)$ & $0.81(0.62-1.06)$ & $\begin{array}{l}p_{\text {non-inf }}=0.0004 \\
p_{s \mathrm{sp}}=0.12\end{array}$ \\
\hline $\begin{array}{l}\text { Combined ischaemic events } \\
\text { (cardiovascular death, } \\
\text { myocardial infarction, stroke) } \\
\text { and all bleeds } \\
\text { (BARC bleeding 1-5) }\end{array}$ & $175(13 \%)$ & $143(11 \%)$ & $0.81(0.65-1.01)$ & 0.06 \\
\hline \multicolumn{5}{|l|}{ Ischaemic events } \\
\hline $\begin{array}{l}\text { Combined ischaemic events } \\
\text { (cardiovascular death, } \\
\text { myocardial infarction, stroke) }\end{array}$ & $42(3 \%)$ & $32(3 \%)$ & $0.77(0.48-1.21)$ & $p_{\text {non-inf }}=0.0115$ \\
\hline Cardiovascular death & $9(1 \%)$ & $7(1 \%)$ & $0.78(0 \cdot 29-2 \cdot 10)$ & 0.63 \\
\hline Myocardial infarction & $28(2 \%)$ & $24(2 \%)$ & $0.86(0.50-1.49)$ & 0.59 \\
\hline Stroke & $7(1 \%)$ & $3(<1 \%)$ & $0.43(0.11-1.67)$ & 0.22 \\
\hline Stent thrombosis (definite) & $3(<1 \%)$ & $2(<1 \%)$ & $0.67(0.11-4.03)$ & 0.66 \\
\hline All-cause mortality & $12(1 \%)$ & $11(1 \%)$ & $0.92(0.41-2.10)$ & 0.85 \\
\hline Urgent revascularisation & $29(2 \%)$ & $40(3 \%)$ & $1.45(0.89-2 \cdot 34)$ & 0.13 \\
\hline \multicolumn{5}{|l|}{ Bleeding events } \\
\hline $\begin{array}{l}\text { Key secondary endpoint (BARC } \\
\text { bleeding } \geq 2 \text { ) }\end{array}$ & $79(6 \%)$ & $64(5 \%)$ & $0.82(0.59-1.13)$ & 0.23 \\
\hline BARC type 1 or 2 & $119(9 \%)$ & $98(8 \%)$ & $0.82(0.63-1.07)$ & 0.15 \\
\hline BARC type 3 or 5 & $20(2 \%)$ & $17(1 \%)$ & $0.85(0.45-1.63)$ & 0.63 \\
\hline Any BARC bleeding & $137(11 \%)$ & $114(9 \%)$ & $0.83(0.65-1.06)$ & 0.14 \\
\hline \multicolumn{5}{|l|}{ Bleeding events } \\
\hline BARC type 1 & $64(5 \%)$ & $52(4 \%)$ & $0.81(0.56-1.17)$ & 0.26 \\
\hline BARC type 2 & $61(5 \%)$ & $47(4 \%)$ & $0.77(0.53-1.13)$ & 0.19 \\
\hline BARC type 3 & $19(2 \%)$ & $17(1 \%)$ & $0.90(0.47-1.73)$ & 0.75 \\
\hline BARC type 4 & $1(<1 \%)$ & $2(<1 \%)$ & $2.02(0.18-22.20)$ & 0.57 \\
\hline BARC type 5 & $1(<1 \%)$ & 0 & .. & 0.89 \\
\hline
\end{tabular}

Data are $n(\%)$. p values presented are for superiority comparisons unless otherwise stated. BARC=Bleeding Academic Research Consortium. $p_{\text {non-inf }}=p$ value for non-inferiority. $p_{\text {sup }}=p$ value for superiority.

Table 3: Clinical outcomes at 12 months' follow-up

511 patients were switched back from clopidogrel to prasugrel, while only five patients with HPR continued clopidogrel based on an individual decision of the treating physician at the follow-up visit. In the control group, a status of HPR was found in 188 patients (14\% of the intention-to-treat population). Adherence to the assigned $\mathrm{P} 2 \mathrm{Y}_{12}$ inhibitor therapy was repeatedly assessed throughout the study in all patients. During the study period of 12 months, adherence to the protocol-mandated treatment was high with a rate of $94.2 \%$ in the control group and $94.4 \%$ in the guided de-escalation group. Use of low-dose ( $5 \mathrm{mg}$ per day) instead of standard dose prasugrel (10 mg per day) for study drug treatment was low $(4.0 \%$ in guided de-escalation group vs $4.2 \%$ in control group) and did not differ between the study groups $(\mathrm{p}=0 \cdot 88)$. During the 1-year study period, 43 patients (2\%) withdrew consent and 110 (4\%) were lost to follow-up (figure 2).
At 1 year, the combined primary endpoint occurred in 95 patients $(7 \%)$ in the guided de-escalation group and in 118 patients $(9 \%)$ in the control group ( $\mathrm{p}_{\text {non-inferiority }}=0.0004 ;$ HR $0.81 \quad[95 \%$ CI $0.62-1.06]$, $\mathrm{p}_{\text {superiority }}=0.12$; table 3 ; figure $3 \mathrm{~A}$ ). The ischaemic components of the primary endpoint (cardiovascular death, myocardial infarction, and stroke) occurred in 32 patients $(3 \%)$ in the guided de-escalation group and in 42 patients (3\%) in the control group (HR 0.77 [95\% CI $0 \cdot 48-1 \cdot 21] ; p=0 \cdot 25$; figure $3 \mathrm{C}$ ), indicating that early de-escalation did not result in an increased risk of cardiovascular death, myocardial infarction, or stroke $\left(\mathrm{p}_{\text {non-inferiority }}=0 \cdot 0115\right)$. Table 3 summarises relevant outcome data for all individual components of the combined ischaemic endpoint. No significant differences were observed for any of the ischaemic components of the primary endpoint $(\mathrm{p} \geq 0 \cdot 22)$ as well as for the rate of urgent revascularisation $(p=0 \cdot 13)$. Allcause mortality at 1 year was $1 \%$ (12 events) in the control group versus $1 \%$ (11 events) in the guided deescalation group $(p=0 \cdot 85)$. The cumulative incidence of definite stent thrombosis was low with two events $(<1 \%)$ in the guided de-escalation group versus three events $(<1 \%)$ in the control group (HR 0.67 [95\% CI 0 11-4.03]; $\mathrm{p}=0 \cdot 66)$.

The incidence of the key secondary endpoint of BARC 2 or higher bleedings was 5\% (64 events) in the guided deescalation group versus $6 \%$ (79 events) in the control group (HR $0 \cdot 82$ [95\% CI 0.59-1.13]; $\mathrm{p}=0 \cdot 23$; figure 3B). The cumulative incidence of all bleeding events (BARC class 1 to 5 ) was $9 \%$ (114 events) in the guided deescalation group versus $11 \%$ (137 events) in the control group (HR 0.83 [95\% CI 0.65-1.06]; $\mathrm{p}=0 \cdot 14$; figure 3D). Table 3 summarises all bleeding events according to BARC types (1 to 5$)$ across groups. Per-protocol analyses yielded similar results to the intention-to-treat analyses for the primary study endpoint (HR 0.84 [95\% CI $0 \cdot 64-1 \cdot 19] ; p_{\text {non-inferiority }}=0.0013$ for guided de-escalation vs control group) and for the key secondary endpoint of BARC 2 or higher bleedings (HR 0.81 [95\% CI $0 \cdot 58-1 \cdot 17$ ]; $\mathrm{p}=0 \cdot 24$ for guided de-escalation $v$ s control group) of the study.

Relevant clinical variables like clinical presentation (STEMI vs non-ST elevation myocardial infarction [NSTEMI]), age, sex, and status for diabetes were subject to post-hoc subgroup analyses for the primary endpoint. For study group comparisons, patients with STEMI $($ HR 0.54 [95\% CI $\left.0 \cdot 35-0 \cdot 83] ; p=0 \cdot 004 ; p_{\text {interaction }}=0 \cdot 0116\right)$ and younger (age $\leq 70$ years) patients $(0 \cdot 70$ [0.51-0.96]; $\mathrm{p}=0 \cdot 0270 ; \mathrm{p}_{\text {interaction }}$ for categorical model $=0 \cdot 11, \mathrm{p}_{\text {interaction }}$ for continuous model $=0.0229)$ showed significant differences favouring guided de-escalation. Figure 4 shows the results of relevant subgroups and their outcomes with respect to the study group. Further analyses of all control group patients versus patients treated with clopidogrel from the guided de-escalation group and on patients treated with prasugrel versus those 


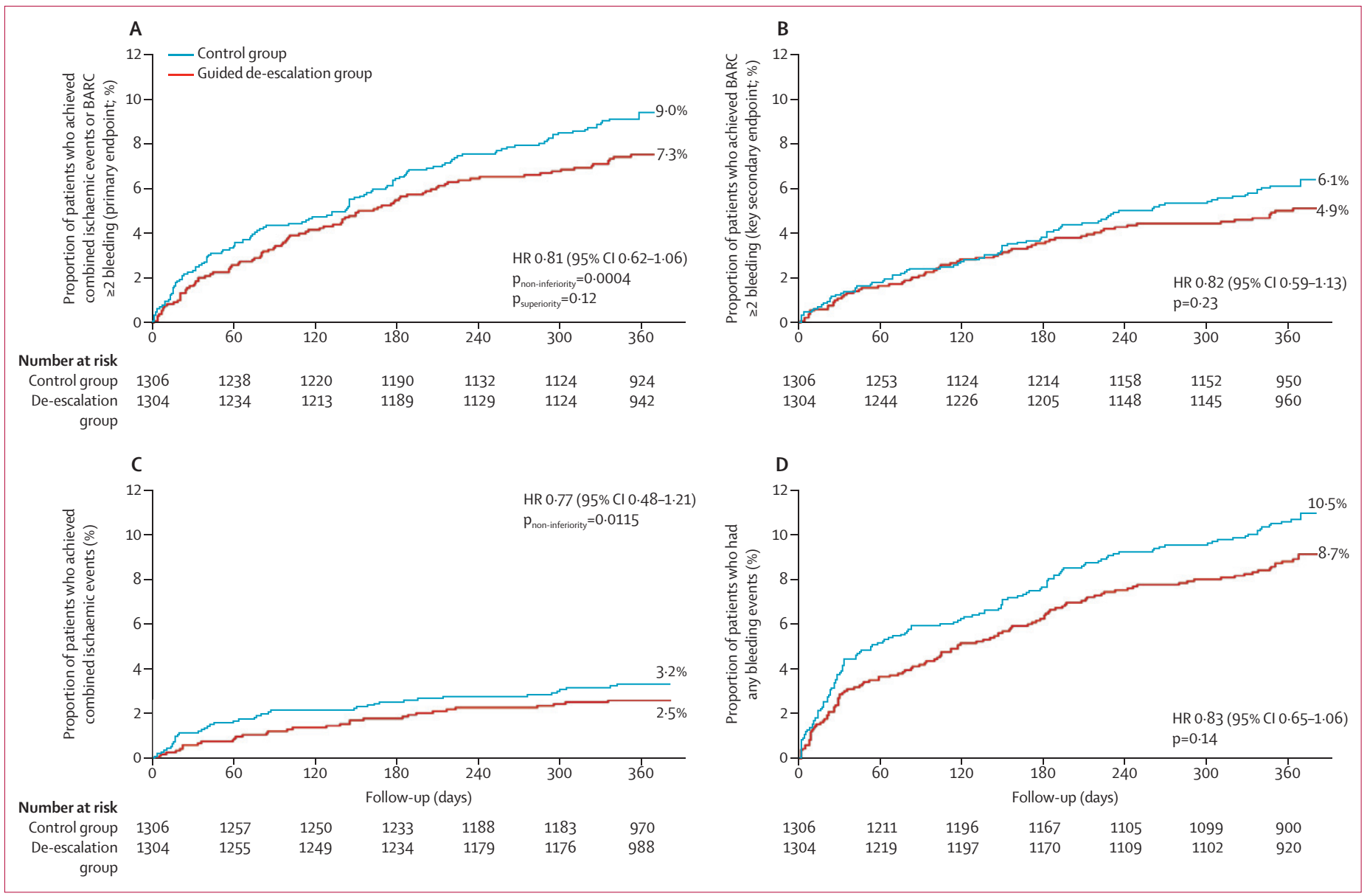

Figure 3: Kaplan-Meier curves for the primary endpoint (net clinical benefit; A), the key secondary endpoint (BARC 2 or higher bleeding; B), the combined ischaemic endpoint (C), and all bleeding events (BARC class 1-5; D) at 12 months' follow-up

$\mathrm{BARC}=$ Bleeding Academic Research Consortium. HR=hazard ratio.

treated with clopidogrel (as-treated analysis) are shown in the appendix (pp 3-4).

\section{Discussion}

De-escalation of antiplatelet treatment after an acute coronary syndrome is conceptually appealing and frequently practised in real-world scenarios. ${ }^{6,8-11,24-26}$ Nevertheless, there is little evidence until now to justify switching regimens. TROPICAL-ACS is currently the only trial investigating a concept of guided de-escalation of $\mathrm{P}_{2} \mathrm{Y}_{12}$ inhibition in an all-comers cohort of patients with acute coronary syndrome. Key findings from this study are that a stage-adapted antiplatelet treatment strategy with initial potent platelet inhibition using prasugrel, followed by guided dual antiplatelet treatment (DAPT) de-escalation to clopidogrel proved to be feasible and non-inferior to conventional 12-month prasugrel therapy. In particular, the rate and distribution of ischaemic events were not increased with guided DAPT de-escalation. Hence, this study identifies guided DAPT de-escalation as an alternative strategy in patients with acute coronary syndrome that are deemed unsuitable for maintained potent platelet inhibition for whatever medical or socioeconomic reasons. ${ }^{9}$

Several further observations are worth mentioning. First, by contrast with previous studies investigating concepts of uniform de-escalation, ${ }^{7,8}$ we used individualised PFT-guided de-escalation in this study. Landmark data $^{3,4}$ from PLATO and TRITON-TIMI 38 trials showed that even though protection from recurrent ischaemia with potent agents was most prominent during the acute phase, it persisted throughout chronic treatment out to 12 months after an acute coronary syndrome. Hence, PFT guidance of de-escalation was applied to guarantee sufficient platelet inhibition in all patients with acute coronary syndrome during their chronic course of treatment. Second, adherence to per-protocol DAPT was higher than in many other recent trials of acute coronary syndrome ${ }^{1,710}$ and ischaemic risk was low in both study groups. These observations could be related to the fact that drug treatment was monitored in all patients enrolled into our trial, which potentially had beneficial effects on 


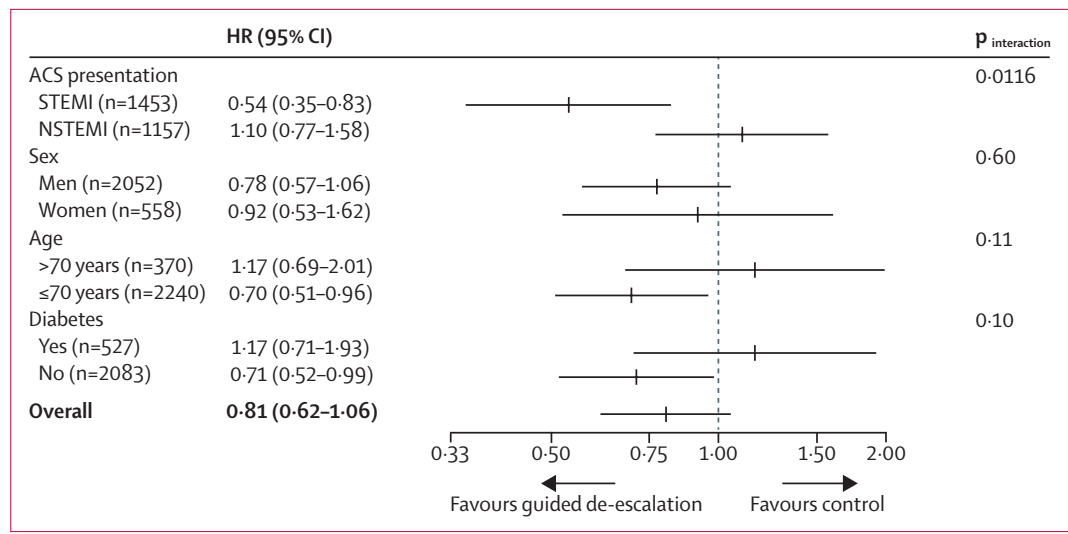

Figure 4: Subgroup analyses

Subgroup analyses of the primary composite endpoint (net clinical benefit) in relevant subgroups of the study cohort (clinical presentation: STEMI/NSTEMI, sex, age, and diabetes). $p_{\text {interaction }}$ represents the likelihood of interaction between the variable and the treatment strategy (platelet function testing-guided de-escalation vs uniform prasugrel treatment). ACS=acute coronary syndrome. HR=hazard ratio. STEMI=ST-segment elevation myocardial infarction. NSTEMI=non-ST-segment elevation myocardial infarction

patient compliance. Third, high drug adherence and follow-up rates within this study proved the feasibility of guided de-escalation as early as 1 week after patient's discharge. DAPT de-escalation seems clinically most relevant when applied early, considering that adverse events, including side-effects and bleeds, occur over time during maintenance therapy. Nevertheless, it seems reasonable to extrapolate from this study that deescalation would also be feasible and safe at later stages during chronic antiplatelet treatment. Further on, the rate of ischaemic events was lower in this study than in previous trials, including TRITON-TIMI 38 and PLATO. ${ }^{1,2}$ It must be emphasised that randomisation in our trial was done before discharge and hence several days after PCI. Thus, early and peri-procedural events that dominated the overall event rates of previous studies ${ }^{1,2}$ were not included in our trial. This together with the increased safety of contemporary PCI with a high rate of radial access and use of latest generation drug-eluting stents (eg, everolimus-eluting or zotarolimus-eluting stents) are likely explanations for the lower risk of ischaemic events in our trial.

Previous trials addressing concepts of de-escalation of antiplatelet treatment are limited and have yielded somewhat conflicting findings. Observational data from the $\mathrm{SCOPE}^{8}$ registry enrolling 1363 patients with acute coronary syndrome showed that de-escalation from potent antiplatelet inhibitors to clopidogrel was independently associated with adverse events during chronic DAPT. By contrast, the recent TOPIC trial ${ }^{7}$ reported that a switch over from ticagrelor or prasugrel to clopidogrel 1 month after PCI for acute coronary syndrome reduced bleeding complications. However, TOPIC differs essentially from this study in various aspects: first, primary endpoint selection (composite of cardiovascular death, unplanned hospital admission leading to urgent coronary revascularisation, stroke, and bleeding episodes as defined by the BARC type $\geq 2$ ) allowing for a smaller sample size to show superiority ( 645 patients in TOPIC vs 2610 patients in TROPICAL-ACS); second, the monocentric study design in TOPIC; third, a moderate adherence (75\%) to treatment in the control group of TOPIC; fourth, TOPIC did not specifically report important ischaemic endpoints like myocardial infarction or stent thrombosis, limiting the conclusions that can be made regarding safety aspects of de-escalation; and most importantly, fifth, TOPIC used uniform de-escalation switching all patients in the deescalation arm from an established potent $\mathrm{P}_{2} \mathrm{Y}_{12}$ inhibitor to the less potent clopidogrel. By contrast, our study accounts for the substantial response variability of clopidogrel ${ }^{12,14,15}$ and considers the persistent anti-ischaemic potential of sufficient platelet inhibition seen during the chronic treatment phase. ${ }^{1,2}$ This is achieved by implementation of drug-response testing precluding deescalation in patients with HPR, carrying a higher risk of thrombotic events in a background of insufficient $\mathrm{P}_{2} \mathrm{Y}_{12}$ inhibitor therapy. ${ }^{14,15}$ Findings from this study show that PFT-tailored de-escalation is safe, because none of the ischaemic endpoints - alone or in combination-tended to be higher in the guided de-escalation group than in the control group. We also did not observe any clustering of thrombotic events during the early phase of treatment after discharge, where antiplatelet drugs were switched per protocol in the guided de-escalation group.

Besides recurrent ischaemia, bleeding complications are among the most frequent adverse events after PCI, both during the acute and even more so during the maintenance phase of treatment. ${ }^{3,4}$ We observed numerically more events across all BARC classes in the control group than in the guided de-escalation group. However, these differences did not reach a level of statistical significance and were most pronounced for minimal and minor bleeds, while we observed no relevant reduction in BARC 3-5 bleeding in the guided de-escalation group. However, even minor bleeds might have important effects on treatment compliance and health-care costs. ${ }^{27-29}$ The relative risk reductions observed for bleeding risk in this study are similar to the differences observed in prasugrel versus clopidogrel study groups in the TRITON-TIMI trial. ${ }^{2}$ Nevertheless, the overall reduction in bleeding risk by de-escalation was smaller than expected, which might at least in part be due to the fact that about $40 \%$ of patients in the guided de-escalation group showed HPR on clopidogrel and continued prasugrel maintenance treatment.

Even though this study uses PFT to back up deescalation in a cohort of patients in which potent platelet inhibition is established and recommended, it should not be considered primarily a PFT study. Nevertheless, our trial needs to be discussed against the background of previous studies using PFT to tailor DAPT. ADAPT-DES ${ }^{15}$ and large meta-analyse ${ }^{14}$ have confirmed the predictive value of PFT for ischaemic and bleeding events after PCI. However, subsequent randomised 
trials implementing PFT for guidance of antiplatelet therapy failed to show a positive effect of testing on patient outcomes. Yet, the concepts of tailored treatment tested in previous trials substantially differ from the approach of guided de-escalation investigated in this study. Earlier trials aimed to test PFT-guided escalation rather than de-escalation of DAPT focusing predominantly ${ }^{30,31}$ or exclusively ${ }^{32}$ on low-risk elective PCI patients. The recent ANTARCTIC trial ${ }^{33}$ is the only previous trial using PFT to tailor DAPT in a dedicated acute coronary syndrome cohort. However, there are substantial differences in study design between ANTARCTIC and this study: ANTARCTIC randomly assigned patients with acute coronary syndrome who were aged 75 years or older to receive oral prasugrel $5 \mathrm{mg}$ daily with or without dose or drug adjustment for escalation or de-escalation depending on platelet function monitoring. In essence, ANTARCTIC compared the effect of prasugrel $5 \mathrm{mg}$ to a regimen in which low-dose prasugrel was replaced by clopidogrel $75 \mathrm{mg}$ in less than half of patients. This is a limitation of ANTARCTIC, because superiority of low dose prasugrel (5 mg) compared with clopidogrel $75 \mathrm{mg}$ with respect to clinical outcomes has never been confirmed. Hence, TROPICAL-ACS is the only trial designed to test PFTguided de-escalation of standard dose prasugrel to clopidogrel in all-comers patients with acute coronary syndrome. Generally, standardised platelet function assays are practical and have already been implemented into clinical routine. ${ }^{34}$ From an economic point of view, costs for PFT are marginal, while cost savings when using off-patent clopidogrel instead of potent platelet inhibitors can be substantial. ${ }^{29}$

Our study population was characterised by a high proportion $(>50 \%)$ of high-risk STEMI patients. STEMI patients derived a net clinical benefit from guided DAPT de-escalation. This is not contradictory to observations made in TRITON-TIMI, ${ }^{35}$ where STEMI patients showed the greatest benefit of potent inhibition very early after PCI, a time frame where also in TROPICAL-ACS both groups received uniform prasugrel treatment. One underlying reason for the positive interaction observed for STEMI patients might be related to the fact that this cohort is characterised by less comorbidities and a lower frequency of multivessel disease when compared with NSTEMI patients. ${ }^{36}$ In fact, the idea of tailored deescalation in STEMI patients was brought up years ago, ${ }^{37}$ based on the results of the STEMI subgroup in TRITONTIMI. ${ }^{35}$ Our study tackles this hypothesis and suggests that STEMI patients could be good candidates for DAPT de-escalation, whenever this is deemed necessary. In addition, younger patients ( $\leq 70$ years), constituting $86 \%$ of the entire study population, also showed favourable outcomes with guided de-escalation. Nevertheless, subgroup analyses should be understood as descriptive and hypothesis generating. Definite answers on what subgroups derive a significant clinical benefit from guided de-escalation would require even larger clinical trials powered to show superiority.

We acknowledge limitations related to our clinical trial. The non-inferiority margin of $30 \%$ chosen for our study can be considered as a potential limitation. However, in post-hoc analyses non-inferiority for the primary endpoint was even maintained with a smaller non-inferiority margin of $10 \%\left(\mathrm{p}_{\text {non-inferiority }}=0 \cdot 0117\right)$. This, together with the fact that both ischaemic as well as bleeding event rates if any were numerically lower, but not higher with guided de-escalation compared with standard treatment, justifies implementation of guided de-escalation as an alternative treatment strategy into clinical practice. Our protocol mandated for choosing prasugrel. Thus, to what extent our findings can be extrapolated to ticagrelor remains unclear. Nevertheless, prasugrel and ticagrelor have very similar $\mathrm{P}_{12}$ inhibitory effects ${ }^{38}$ and a randomised study comparing the two drugs in patients with acute coronary syndrome showed similar efficacy and safety outcomes. ${ }^{10}$ This suggests that our findings could indeed apply to patients with acute coronary syndrome treated with ticagrelor. TROPICAL-ACS was planned as an all-comers trial and did not preferentially enrol patients susceptible to bleeding complications, even though they represent potential and excellent candidates for PFT guided deescalation and are more likely to de-escalate DAPT postdischarge based on large observational registries. ${ }^{9}$ However, patients susceptible to bleeding complications were also excluded from the PLATO and TRITON-TIMI 38 trials. ${ }^{1,2}$ Hence, whether these patients derive a net clinical benefit from potent platelet inhibitors in the first place is unclear. As a consequence, enrolment of patients susceptible to bleeding into a trial using prasugrel in one study arm is probably limited by preferential upfront use of clopidogrel in these patients and the reduced adherence to potent platelet inhibition. Finally, further limitations of our trial are the open-label design, the exclusion of patients with a history of stroke, and the proportion of patients lost to follow-up, which was $4 \%$ in both study groups.

In conclusion, a guided de-escalation of antiplatelet treatment was non-inferior to standard treatment with prasugrel in terms of net clinical benefit. A concept of guided de-escalation was characterised by a high rate of adherence to treatment and proved feasible in clinical practice. Together, our trial provides important evidence for patients with acute coronary syndrome after successful PCI in whom early de-escalation is considered as an alternative strategy.

\section{Contributors}

DS, SM, JM, and DA designed the study and analysed and interpreted the data. DS, SM, F-JN, JM, KH, LK, and DA participated to the steering committee, contributed to implementation of the study, enrolment, and follow-up of patients, and revised the manuscript. CJ, LG, DT, TG, MO, $\mathrm{MH}, \mathrm{BM}, \mathrm{RGK}, \mathrm{AK}, \mathrm{CAD}, \mathrm{LH}, \mathrm{SBF}, \mathrm{RP}, \mathrm{MK}, \mathrm{RHGS}, \mathrm{JR}$, and ZH contributed to the implementation of the study, enrolment and follow-up of patients, and review of the manuscript. MH did all statistical analyses. 
DS, DA, and SM wrote the first draft and submitted the final version for publication. All authors have seen the version of the article and agree with the content and conclusions.

\section{TROPICAL-ACS Investigators}

Steering Committee: Steffen Massberg (Munich, Germany), Dirk Sibbing (Munich, Germany), Julinda Mehilli (Munich, Germany), Jörg Hausleite (Munich, Germany), Franz-Josef Neumann (Bad Krozingen, Germany), Kurt Huber (Vienna, Austria), Daniel Aradi (Balatonfüred, Hungary), Lukasz Koltowski (Warsaw, Poland)

Project Management: CSC ${ }^{\mathrm{LMU}}$, Clinical Study Center, Ludwig-MaximiliansUniversität München (Munich, Germany)

Study Monitoring and Data Management: Monitoring Institution:

Münchner Studienzentrum (MSZ) (Munich, Germany); Data

Management: Technische Universität Dresden (KKS)

Data and Safety Monitoring Board: Albert Schömig (Munich, Germany),

Helmut Schühlen (Berlin, Germany), Martin Hadamitzky (Munich, Germany)

Event Adjudication Committee: Jürgen Pache (Tutzing, Germany), Ute Wilbert-Lampen (Munich, Germany), Dritan Poci (Sweden)

\section{Declaration of interests}

DS reports grants from Roche Diagnostics and Daiichi Sankyo during the conduct of the study; and personal fees from Bayer AG, Daiichi Sankyo, Eli Lilly, Roche Diagnostics, MSD, Pfizer, and AstraZeneca outside of the submitted work. DA reports personal fees from Roche Diagnostics, DSI/Lilly, AstraZeneca, Pfizer, Bayer AG, and MSD Pharma outside of the submitted work. DT reports personal fees from AstraZeneca, Bayer, Boehringer Ingelheim, Bristol-Myers Squibb, Daiichi Sankyo, Eli Lilly, and Sanofi; and personal fees from Otsuka outside of the submitted work. TG reports personal fees from AstraZeneca, grants and personal fees from Bayer Healthcare, personal fees from Boehringer Ingelheim, grants and personal fees from Bristol-Myers Squibb, personal fees from Pfizer, grants and personal fees from Daiichi Sankyo, grants and personal fees from Eli Lilly, grants and personal fees from The Medicines Company, personal fees from MSD, grants from Siemens Healthcare, and grants from Spartan Bioscience outside of the submitted work. BM reports personal fees from MSD Pharma, Bayer AG, Boehringer Ingelheim, Pfizer, and AstraZeneca outside of the submitted work. RGK reports personal fees from Pfizer, Boehringer Ingelheim, Bayer, MSD, and AstraZeneca outside of the submitted work. AK reports personal fees from Bayer AG and Pfizer outside of the submitted work. SBF reports personal fees from Daiichi Sankyō outside of the submitted work. F-JN reports grants and non-financial support from Daiichi Sankyō during the conduct of the study; grants from Boston Scientific, grants and non-financial support from Edwards, grants from Medtronic, grants from Biotronic, grants from AstraZeneca, non-financial support from Boehringer, non-financial support from Pfizer, grants from St Jude, and grants from Abbottt Vascular, outside of the submitted work. JM reports grants and personal fees from Abbott Vascular and Edwards LifeScience, and personal fees from Terumo, BMS, Lilly/Daiichi Sankyo, and Biotronik outside of the submitted work. ZH reports personal fees from AstraZeneca, Bayer, Aspen, Polpharma, and Abbott, and personal fees from Medtronic outside of the submitted work. All other authors declare no competing interests.

\section{Acknowledgments}

TROPICAL-ACS is an independent, investigator-initiated trial, with an academic sponsor (Klinikum der Universität München, Munich, Germany). The trial was financially supported by a research grant from Roche Diagnostics (Rotkreuz, Switzerland). Prasugrel purchase, drug delivery, and related logistics were kindly supported by Eli Lilly and Company and Daiichi Sankyo Company. The valuable project management work of Monika Baylacher (LMU München, Munich, Germany) throughout the entire trial is kindly acknowledged. We also acknowledge the valuable work on data management by Katja Wendrich (TU Dresden, KKS, Dresden, Germany) and the work on study drug preparation by Andreas Thalmeier (LMU München, Munich, Germany)

\section{References}

1 Wallentin L, Becker RC, Budaj A, et al. Ticagrelor versus

clopidogrel in patients with acute coronary syndromes.

N Engl J Med 2009; 361: 1045-57.
2 Wiviott SD, Braunwald E, McCabe $\mathrm{CH}$, et al. Prasugrel versus clopidogrel in patients with acute coronary syndromes. N Engl J Med 2007; 357: 2001-15.

3 Antman EM, Wiviott SD, Murphy SA, et al. Early and late benefits of prasugrel in patients with acute coronary syndromes undergoing percutaneous coronary intervention: a TRITON-TIMI 38 (TRial to Assess Improvement in Therapeutic Outcomes by Optimizing Platelet InhibitioN with Prasugrel-Thrombolysis In Myocardia Infarction) analysis. J Am Coll Cardiol 2008; 51: 2028-33.

4 Becker RC, Bassand JP, Budaj A, et al. Bleeding complications with the P2Y12 receptor antagonists clopidogrel and ticagrelor in the PLATelet inhibition and patient Outcomes (PLATO) trial. Eur Heart J 2011; 32: 2933-44.

5 Roffi M, Patrono C, Collet JP, et al. 2015 ESC Guidelines for the management of acute coronary syndromes in patients presenting without persistent ST-segment elevation: Task Force for the Management of Acute Coronary Syndromes in Patients Presenting without Persistent ST-Segment Elevation of the European Society of Cardiology (ESC). Eur Heart J 2016; 37: 267-315.

6 Rollini F, Franchi F, Angiolillo DJ. Switching P2Y12-receptor inhibitors in patients with coronary artery disease. Nat Rev Cardiol 2016; 13: 11-27.

7 Cuisset T, Deharo P, Quilici J, et al. Benefit of switching dual antiplatelet therapy after acute coronary syndrome: the TOPIC (timing of platelet inhibition after acute coronary syndrome) randomized study. Eur Heart J 2017; published online May 16. DOI:10.1093/eurheartj/ehx175

8 De Luca L, D’Ascenzo F, Musumeci G, et al. Incidence and outcome of switching of oral platelet p2y12 receptor inhibitors in patients with acute coronary syndromes undergoing percutaneous coronary intervention: the SCOPE registry. EuroIntervention 2017; 13: 459-66.

9 Zettler ME, Peterson ED, McCoy LA, et al. Switching of adenosine diphosphate receptor inhibitor after hospital discharge among myocardial infarction patients: Insights from the Treatment with Adenosine Diphosphate Receptor Inhibitors: Longitudinal Assessment of Treatment Patterns and Events after Acute Coronary Syndrome (TRANSLATE-ACS) observational study. Am Heart J 2017; 183: 62-68.

10 Motovska Z, Hlinomaz O, Miklik R, et al. Prasugrel versus ticagrelor in patients with acute myocardial infarction treated with primary percutaneous coronary intervention: multicenter randomized PRAGUE-18 study. Circulation 2016; 134: 1603-12.

11 Dery JP, Mehta SR, Fisher HN, et al. Baseline characteristics, adenosine diphosphate receptor inhibitor treatment patterns, and in-hospital outcomes of myocardial infarction patients undergoing percutaneous coronary intervention in the prospective Canadian Observational AntiPlatelet sTudy (COAPT). Am Heart J 2016; 181: 26-34.

12 Gurbel PA, Bliden KP, Hiatt BL, O'Connor CM. Clopidogrel for coronary stenting: response variability, drug resistance, and the effect of pretreatment platelet reactivity. Circulation 2003; 107: 2908-13.

13 Tantry US, Bonello L, Aradi D, et al. Consensus and update on the definition of on-treatment platelet reactivity to adenosine diphosphate associated with ischemia and bleeding. J Am Coll Cardiol 2013; 62: 2261-73.

14 Aradi D, Kirtane A, Bonello L, et al. Bleeding and stent thrombosis on P2Y12-inhibitors: collaborative analysis on the role of platelet reactivity for risk stratification after percutaneous coronary intervention. Eur Heart J 2015; 36: 1762-71.

15 Stone GW, Witzenbichler B, Weisz G, et al. Platelet reactivity and clinical outcomes after coronary artery implantation of drug-eluting stents (ADAPT-DES): a prospective multicentre registry study. Lancet 2013; 382: 614-23.

16 Sibbing D, Aradi D, Jacobshagen C, et al. A randomised trial on platelet function-guided de-escalation of antiplatelet treatment in ACS patients undergoing PCI. Rationale and design of the Testing Responsiveness to Platelet Inhibition on Chronic Antiplatelet Treatment for Acute Coronary Syndromes (TROPICAL-ACS) Trial. Thromb Haemost 2017; 117: 188-95.

17 Amsterdam EA, Wenger NK, Brindis RG, et al. 2014 AHA/ACC Guideline for the Management of Patients with Non-ST-Elevation Acute Coronary Syndromes: a report of the American College of Cardiology/American Heart Association Task Force on Practice Guidelines. J Am Coll Cardiol 2014; 64: e139-228. 
18 Thygesen K, Alpert JS, Jaffe AS, Simoons ML, Chaitman BR, White HD. Third universal definition of myocardial infarction. Eur Heart J 2012; 33: 2551-67.

19 Mehran R, Rao SV, Bhatt DL, et al. Standardized bleeding definitions for cardiovascular clinical trials: a consensus report from the Bleeding Academic Research Consortium. Circulation 2011; 123: 2736-47.

20 Cutlip DE, Windecker S, Mehran R, et al. Clinical end points in coronary stent trials: a case for standardized definitions. Circulation 2007; 115: 2344-51.

21 Ndrepepa G, Schuster T, Hadamitzky M, et al. Validation of the Bleeding Academic Research Consortium definition of bleeding in patients with coronary artery disease undergoing percutaneous coronary intervention. Circulation 2012; 125: 1424-31.

22 Feres F, Costa RA, Abizaid A, et al. Three vs twelve months of dual antiplatelet therapy after zotarolimus-eluting stents: the OPTIMIZE randomized trial. JAMA 2013; 310: 2510-22.

23 Granger CB, Alexander JH, McMurray JJ, et al. Apixaban versus warfarin in patients with atrial fibrillation. N Engl J Med 2011; 365: 981-92.

24 Sheikh Rezaei S, Geroldinger A, Heinze G, Reichardt B, Wolzt M. Clopidogrel, prasugrel, or ticagrelor use and clinical outcome in patients with acute coronary syndrome: a nationwide long-term registry analysis from 2009 to 2014. Int J Cardiol 2017; 235: 61-66.

25 Karve AM, Seth M, Sharma M, et al. Contemporary Use of Ticagrelor in Interventional Practice (from Blue Cross Blue Shield of Michigan Cardiovascular Consortium). Am J Cardiol 2015; 115: 1502-06.

26 Bagai A, Wang Y, Wang TY, et al. In-hospital switching between clopidogrel and prasugrel among patients with acute myocardial infarction treated with percutaneous coronary intervention: insights into contemporary practice from the national cardiovascular data registry. Circ Cardiovasc Interv 2014; 7: 585-93.

27 Czarny MJ, Nathan AS, Yeh RW, Mauri L. Adherence to dual antiplatelet therapy after coronary stenting: a systematic review. Clin Cardiol 2014; 37: 505-13.

28 Cutlip DE, Kereiakes DJ, Mauri L, Stoler R, Dauerman HL, Investigators E. Thrombotic complications associated with early and late nonadherence to dual antiplatelet therapy. JACC Cardiovasc Interv 2015; 8: 404-10.

29 Straub N, Beivers A, Lenk E, Aradi D, Sibbing D. A model-based analysis of the clinical and economic impact of personalising P2Y12-receptor inhibition with platelet function testing in acute coronary syndrome patients. Thromb Haemost 2014; 111: 290-99.
30 Price MJ, Berger PB, Teirstein PS, et al. Standard- vs high-dose clopidogrel based on platelet function testing after percutaneous coronary intervention: the GRAVITAS randomized trial. JAMA 2011; 305: 1097-105.

31 Collet JP, Cuisset T, Range G, et al. Bedside monitoring to adjust antiplatelet therapy for coronary stenting. N Engl J Med 2012; 367: 2100-09.

32 Trenk D, Stone GW, Gawaz M, et al. A randomized trial of prasugrel versus clopidogrel in patients with high platelet reactivity on clopidogrel after elective percutaneous coronary intervention with implantation of drug-eluting stents: results of the TRIGGER-PCI (testing platelet reactivity in patients undergoing elective stent placement on clopidogrel to guide alternative therapy with prasugrel) Study. J Am Coll Cardiol 2012; 59: 2159-64.

33 Cayla G, Cuisset T, Silvain J, et al. Platelet function monitoring to adjust antiplatelet therapy in elderly patients stented for an acute coronary syndrome (ANTARCTIC): an open-label, blinded-endpoint, randomised controlled superiority trial. Lancet 2016; 388: 2015-22.

34 Aradi D, Tornyos A, Pinter T, et al. Optimizing P2Y12 receptor inhibition in patients with acute coronary syndrome on the basis of platelet function testing: impact of prasugrel and high-dose clopidogrel. J Am Coll Cardiol 2014; 63: 1061-70.

35 Montalescot G, Wiviott SD, Braunwald E, et al. Prasugrel compared with clopidogrel in patients undergoing percutaneous coronary intervention for ST-elevation myocardial infarction (TRITON-TIMI 38): double-blind, randomised controlled trial. Lancet 2009; 373: 723-31.

36 Ndrepepa G, Mehilli J, Schulz S, et al. Patterns of presentation and outcomes of patients with acute coronary syndromes. Cardiology 2009; 113: 198-206.

37 Stone GW. Ischaemia versus bleeding: the art of clinical decision-making. Lancet 2009; 373: 695-96.

38 Rollini F, Franchi F, Cho JR, et al. A head-to-head pharmacodynamic comparison of prasugrel vs. ticagrelor after switching from clopidogrel in patients with coronary artery disease: results of a prospective randomized study. Eur Heart $J$ 2016; 37: $2722-30$. 


\section{Dual antiplatelet therapy guided by platelet function testing @}

Oral $\mathrm{P}_{2} \mathrm{Y}_{12}$ receptor inhibitors are key for secondary prevention of atherothrombotic events in patients with acute coronary syndromes, in particular those undergoing percutaneous coronary intervention $(\mathrm{PCl})^{1}$. Prasugrel and ticagrelor are more potent than clopidogrel, which is characterised by increased rates of high ontreatment platelet reactivity (HPR), a known marker for recurrent ischaemic events, including stent thrombosis. ${ }^{2}$ This characteristic could explain the greater reduction in atherothrombotic events, albeit at the expense of more bleeding, associated with prasugrel and ticagrelor therapy among patients with acute coronary syndromes undergoing $\mathrm{PCl}^{1}{ }^{1}$ These observations have stimulated research aimed at understanding how to implement platelet function testing (PFT) to guide the selection of $\mathrm{P}^{2} \mathrm{Y}_{12}$ inhibiting therapies. ${ }^{3}$ However, previous randomised controlled trials (RCTs) using PFT have failed to show any effect on clinical outcomes and thus PFT is not recommended for routine use. ${ }^{4-7}$

In The Lancet, Dirk Sibbing and colleagues ${ }^{8}$ report the results of the TROPICAL-ACS trial, which investigated the safety and efficacy of early de-escalation of antiplatelet treatment from prasugrel to clopidogrel guided by PFT. 2610 patients with acute coronary syndrome undergoing $\mathrm{PCl}$ were randomly assigned to standard treatment with prasugrel for 12 months (control group; $\mathrm{n}=1306$ ) or a de-escalation regimen (1 week prasugrel followed by 1 week of clopidogrel and PFT-guided maintenance therapy with clopidogrel or prasugrel from day 14 after hospital discharge; guided de-escalation group; $\mathrm{n}=1304$ ). The primary endpoint (a composite of ischaemic and bleeding events at 1 year) was met $(7.3 \%$ in the de-escalation group vs $9.0 \%$ in the control group; $p_{\text {non-inferiority }}=0.0004$; hazard ratio $[H R]$ $0.81[95 \%$ Cl $\left.0.62-1.06], p_{\text {superiority }}=0.12\right)$, supporting the non-inferiority hypothesis of a guided de-escalation strategy compared with standard treatment with prasugrel (control). De-escalation did not result in an increase in ischaemic events $(2.5 \%$ in the de-escalation group vs $3.2 \%$ in the control group; $p_{\text {non-inferiority }}=0.0115$ ), and there were no differences in the key secondary endpoint of Bleeding Academic Research Consortium criteria type 2 or higher bleeding $(4.9 \%$ in the deescalation group vs $6.1 \%$ in the control group; HR 0.82 [95\% Cl 0.59-1.13]; $p=0.2257$ ). The authors should be commended for this investigation, which is the first to my knowledge to test PFT-guided de-escalation therapy in patients with acute coronary syndrome undergoing $\mathrm{PCl}$ and meets its primary endpoint (appendix). ${ }^{4-8}$ Indeed, differences in trial design, patient risk-profiles, and antiplatelet treatment regimens, among other variables, might explain the different outcomes across RCTs (appendix). ${ }^{4-8}$ Additionally, TROPICAL-ACS further expands on the topic of de-escalation, which has yielded conflicting findings in recently reported studies performed without PFT guidance. ${ }^{9,10}$

Based on the non-inferiority trial design, the take-home message of TROPICAL-ACS is that, in patients with acute coronary syndrome undergoing $\mathrm{PCl}$, PFT-guided selection of $\mathrm{P}_{2} \mathrm{Y}_{12}$ inhibiting therapy could represent an alternative approach to a standard strategy of prasugrel use. Although it might be argued that the non-inferiority margin of $30 \%$ is broad, a post-hoc analysis showed that the non-inferiority was maintained by applying a margin of $10 \%$. The absence of an increase in ischaemic events, but no reduction in bleeding complications, needs to be viewed in light of the trial strategy. In fact, while the PFT-guided strategy in TROPICAL-ACS helped to prevent ischaemic events by minimising the HPR status, this could have contributed to the absence of differences in bleeding between groups due to the fact that following de-escalation about $40 \%$ of patients had HPR and required escalation to prasugrel therapy, reducing the chances to observe a safety

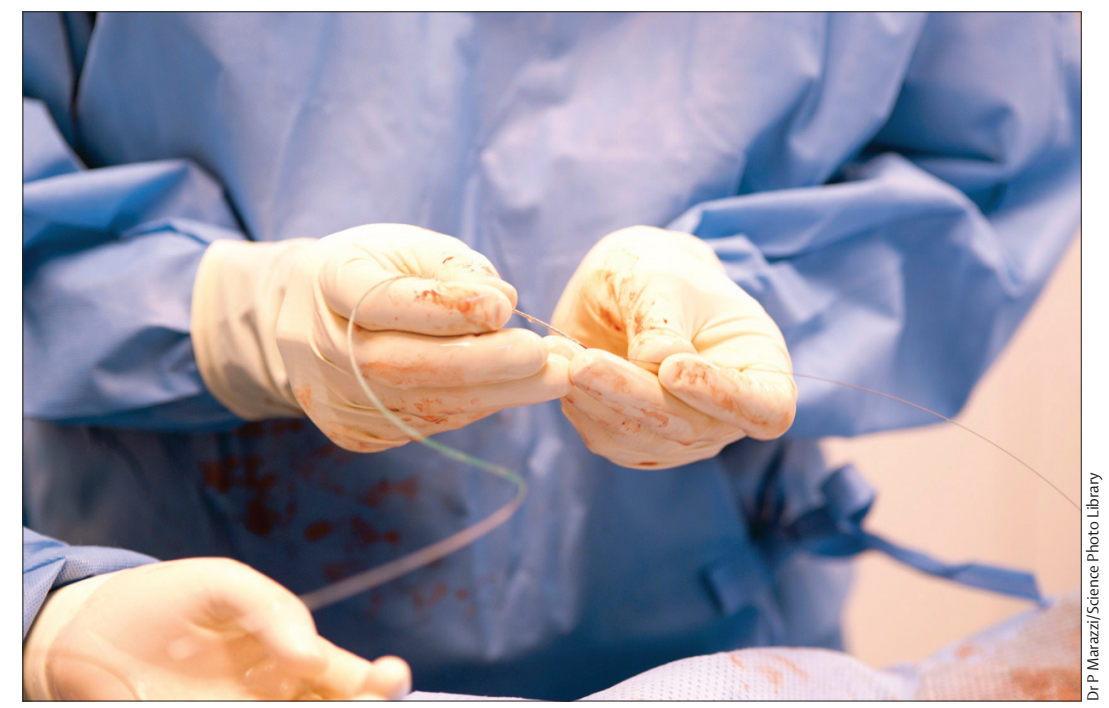

Published Online August 27, 2017 http://dx.doi.org/10.1016/ S0140-6736(17)32279-1 See Online/Articles http://dx.doi.org/10.1016/ S0140-6736(17)32155-4

See Online for appendix 
benefit. ${ }^{8}$ From a practical perspective, a strategy of PFTguided de-escalation therapy might be useful in patients who might not be suitable for prolonged therapy with potent $\mathrm{P} 2 \mathrm{Y}_{12}$ inhibitors, such as those at increased risk of bleeding or with limited access to extended treatment with the more costly prasugrel. Indeed, bleeding concerns and socioeconomic factors are key contributors to de-escalation therapy in real-world practice. ${ }^{11}$

There are some limitations of TROPICAL-ACS. First, although easy-to-use PFT is broadly available, there are a substantial number of HPR patients after de-escalation who then need to escalate therapy. This so-called back and forth management of antiplatelet therapy can be a source of confusion for some patients and might also be challenging to implement if patients cannot easily access centres that conduct PFT. Moreover, multiple factors can contribute to the variability in PFT results and thus defining the HPR status. ${ }^{3}$ Strategies that can overcome the above mentioned limitations are needed. To this extent, genetic testing might be of potential value and is currently under investigation. ${ }^{12}$ Although prasugrel and ticagrelor achieve similar levels of $P 2 Y_{12}$ inhibition, it might be argued that the study findings cannot be extrapolated to ticagrelor because its off-target effects have been advocated to contribute to its overall benefits. ${ }^{1}$ Another consideration to be made is that the study findings cannot be applied to all patients with acute coronary syndromes because elderly individuals, patients with a previous cerebrovascular event, and those with medically managed acute coronary syndrome were excluded.

Despite the diagnostic value of PFT, over the past decade, RCTs have failed to show its role in guiding the choice of antiplatelet therapy. In turn, PFT has struggled to find a space in routine clinical practice. The experience from previous studies led to the design of the TROPICAL-ACS trial, the results of which now provide additional insights on how to use PFT to help select a $P 2 Y_{12}$ inhibitor, thus suggesting a potential resurgence of a nearly abandoned instrument. Future research should build upon TROPICAL-ACS to help to define antiplatelet treatment approaches associated with optimal safety and efficacy performance profiles for the individual patient.

\section{Dominick J Angiolillo}

University of Florida College of Medicine-Jacksonville, Jacksonville, FL 32209, USA

dominick.angiolillo@jax.ufl.edu

I have received payments as an individual for consulting and honorarium from Amgen, Aralez, AstraZeneca, Bayer, Biosensors, Bristol-Myers Squibb, Chiesi, Daiichi-Sankyo, Eli Lilly, Janssen, Merck, PLx Pharma, Pfizer, Sanofi, and The Medicines Company for cangrelor (which no longer belongs to this maker); for participation in review activities from CeloNova and St Jude Medical; and institutional payments for grants from Amgen, AstraZeneca, Bayer, Biosensors, CeloNova, CSL Behring, Daiichi-Sankyo, Eisai, Eli Lilly, Gilead, Janssen, Matsutani Chemical Industry Co, Merck, Novartis, Osprey Medical, and Renal Guard Solutions, all outside of the area of work discussed here. In addition, I have recieved funding from the Scott R MacKenzie Foundation and the NIH/NCATS Clinical and Translational Science Award to the University of Florida UL1TR000064 and NIH/NHGRI U01 HG007269.

1 Franchi F, Angiolillo DJ. Novel antiplatelet agents in acute coronary syndrome. Nat Rev Cardiol 2015; 12: 30-47.

2 Tantry US, Bonello L, Aradi D, et al. Consensus and update on the definition of on treatment platelet reactivity to adenosine diphosphate associated with ischemia and bleeding. J Am Coll Cardiol 2013; 62: 2261-73.

3 Franchi F, Rollini F, Cho JR, Ferrante E, Angiolillo DJ. Platelet function testing in contemporary clinical and interventional practice. Curr Treat Options Cardiovasc Med 2014; 16: 300.

4 Price MJ, Berger PB, Teirstein PS, et al. Standard-vs high-dose clopidogrel based on platelet function testing after percutaneous coronary intervention: the GRAVITAS randomized trial. JAMA 2011; 305: 1097-105.

5 Trenk D, Stone GW, Gawaz M, et al. A randomized trial of prasugrel versus clopidogrel in patients with high platelet reactivity on clopidogrel after elective percutaneous coronary intervention with implantation of drug-eluting stents: results of the TRIGGER-PCI (testing platelet reactivity in patients undergoing elective stent placement on clopidogrel to guide alternative therapy with prasugrel) study. J Am Coll Cardiol 2012 59: $2159-64$

6 Collet JP, Cuisset T, Range G, et al. Bedside monitoring to adjust antiplatelet therapy for coronary stenting. N EnglJ Med 2012; 367: 2100-09.

7 Cayla G, Cuisset T, Silvain J, et al. Platelet function monitoring to adjust antiplatelet therapy in elderly patients stented for an acute coronary syndrome (ANTARCTIC): an open label, blinded-endpoint, randomised controlled superiority trial. Lancet 2016; 388: 2015-22.

8 Sibbing D, Aradi D, Jacobshagen C, et al, on behalf of the TROPICAL-ACS Investigators. Guided De-Escalation of Antiplatelet Treatment in Acute Coronary Syndrome Patients Undergoing percutaneous coronary intervention (TROPICAL-ACS): a randomised, open-label, multicentre trial. Lancet 2017; published online Aug 27. http://dx.doi.org/10.1016/S01406736(17)32155-4

9 Cuisset T, Deharo P, Quilici J, et al. Benefit of switching dual antiplatelet therapy after acute coronary syndrome: the TOPIC (timing of platelet inhibition after acute coronary syndrome) randomized study. Eur Heart 2017; published online May 16. DOI:10.1093/eurheartj/ehx175.

10 De Luca L, D'Ascenzo F, Musumeci G, et al. Incidence and outcome of switching of oral platelet $\mathrm{p} 2 \mathrm{y} 12$ receptor inhibitors in patients with acute coronary syndromes undergoing percutaneous coronary intervention: the SCOPE registry. Eurolntervention 2017; 13: 459-66.

11 Rollini F, Franchi F, Angiolillo DJ. Switching P2Y12-receptor inhibitors in patients with coronary artery disease. Nat Rev Cardiol 2016; 13: 11-27.

12 Moon JY, Franchi F, Rollini F, et al. Role of genetic testing in patients undergoing percutaneous coronary intervention. Expert Rev Clin Pharmacol 2017; published online July 10. DOI:10.1080/17512433.2017.1353909. 